\title{
Evaluation of patients treated for diabetic retinopathy: an analysis of the administrative databases of the Lazio Region
}

\author{
Francesco Saverio Mennini ${ }^{1,2}$, Lorella Lombardozzi ${ }^{3}$, Alessandra Mecozzi ${ }^{4}$, \\ Paolo Sciattella ${ }^{1,5}$ \\ Economic Evaluation and HTA (EEHTA) - CEIS, Faculty of University of Rome "Tor Vergata", Rome \\ Institute for Leadership and Management in Health, Kingston University, London \\ Manager Pharmaceutical Resources Area, Lazio Region, Rome \\ Director of the UOC of the Pharmacy Hospital of Latina, Latina (Rome) \\ Department of Statistical Sciences, "Sapienza University" of Rome, Rome
}

\begin{abstract}
BACKGROUND: In Italy there are an estimated 4 million patients suffering from diabetes mellitus (DM). The most important ocular complication of DM is diabetic retinopathy (DR), which affects about one third of diabetic patients.

AIMS: To identify, within the Lazio Region, the cohort of patients starting treatment for DME in the years 2010-2016 and calculating the annual cost of therapy; and to assess the appropriateness of the drugs prescribed.

METHODS: From the Health Information System of the Lazio Region were identified all subjects who, in the 2010-2016 period, had received at least one prescription for dexamethasone intravitreal implant (i.i.) or intravitreal triamcinolone or ranibizumab or aflibercept or bevacizumab. For the cohort of users selected, the appropriateness of the treatment were evaluated calculating the number of administrations performed in the first four months of the index prescription and the number of administrations performed during the 12 months of treatment.

RESULTS: In 2016, 7,265 patients in the Lazio Region received at least one prescription of ranibizumab (43.0\%), aflibercept $(37.5 \%)$ and dexamethasone i.i. (19.5\%). Among the 3,416 patients naïve at 6 months, who started treatment in the 2013-2015 period and who did not switch to different drugs, $78.7 \%$ started treatment with ranibizumab, $16.0 \%$ with dexamethasone i.i. and 5.3\% with aflibercept. The mean annual cost for the treatment of a patient with DME and naïve at 6 months was equal to $€ 2,388$; a total cost for only the naïve patients selected in the 2013-2015 period is therefore estimated at approximately $€ 8.2$ million. The average annual cost of dexamethasone i.i. treatment was $€ 1,497$, lower than that of ranibizumab $(€ 2,562)$ and aflibercept $(€ 2,485)$. The expenditure for patients receiving less than 3 administrations of ranibizumab or aflibercept in the first 10 months of treatment was estimate equal to $€ 1.3$ million.

CONCLUSIONS: The administrations of dexamethasone i.i. are in line with what is indicated in the prescribing information, while for ranibizumab and aflibercept a potential under-use has been identified. A greater appropriateness of the drugs prescribed, accompanied by an optimal adherence to therapy, would strongly reduce the current waste of resources.
\end{abstract}

\section{Keywords}

Diabetic Retinopathy; Italy, Vascular Endothelial Growth Factor

\section{INTRODUCTION}

In Italy there are an estimated 4 million patients suffering from diabetes mellitus (DM), with a prevalence equal to $6.2 \%$, which however can reach $8 \%$ if the cases of unknown diabetes - which, according to the Osservatorio ARNO data, correspond to $20-30 \%$ of the total (about 1 million Italians) - are also considered [1].

The increase in diabetes cases is closely related to three conditions: the aging of the population, the progressive increase in obesity and the worsening of the socio-economic status [2].

The improvement in the diagnostic-therapeutic standards led to a significant reduction in mortality due to DM, which is however associated with an increased level of disability, that in turn led to the emergence of new social and health issues [3]. The management costs of DM, in fact, have increased over time: currently, they amount to about $€ 20$ billion a year, of

Corresponding author Francesco Saverio Mennini f.mennini@uniroma2.tt Received: 28 June 2019 Accepted: 5 September 2019 Published: 8 November 2019 
which $€ 9$ billion due to direct medical costs (drugs, hospitalization and care) and almost $€ 11$ billion absorbed by indirect and social costs, such as the loss of productivity (also on the part of caregivers) and the permanent disability and early retirement costs borne by the Social Security system [4]. Moreover, a recent study has shown that half of diabetic patients suffer from at least two other comorbidities, leading to further expenses borne by the health system [5].

Complications associated with DM mainly affect the peripheral nervous system, the cardiovascular system, the kidneys and the visual apparatus. The most important ocular complication of DM is diabetic retinopathy (DR), recognized as the main cause of acquired blindness in working age adults in industrialized Countries [6-9]. Epidemiological data show that DR is present in about one third of diabetic patients, while severe forms - including diabetic macular edema (DME) - affect $2 \%$ of DM patients [6,10]. Progressively growing numbers in diabetes and its related complications suggest the need for interventions aimed on the one hand at preventing diabetes, and on the other at improving the management of diabetic patients and the treatment of complications.

On the basis of the considerations and analyses reported so far, the present work has set the goal of:

1. identifying, within the Lazio Region, the cohort of patients starting treatment for DME in the years 2010-2016 and calculating the annual cost of therapy;

2. assessing the appropriateness of the drugs prescribed according to the information reported in the SmPC.

\section{METHODS}

\section{Data source}

The study is based on data extracted from the Health Information System of the Lazio Region relating to the years 2010-2016. The pharmaceutical prescriptions have been extracted from the pharmaceutical prescriptions information systems: DataWareHouse (DWH) and FarmED.

The DWH contains all the prescriptions forwarded by municipal and private pharmacies present in the regional territory for patients residing in the Lazio Region and reimbursed by the NHS (class A drugs), while the FarmED records the pharmaceutical services provided directly by the health facilities. In both databases, drugs are registered with their MA (Marketing Authorization) code, which allows the identification of the active ingredient (ATC code: Anatomical Therapeutic Chemical classification) and the dosage. For each prescription, the quantity dispensed, the date of shipment of the drug, the price, and the individual, anonymized data of the patient are reported.

Hospitalizations were selected by the Hospital Information System (SIO, Sistema Informativo Ospedaliero), which identifies and manages the analytical data of all hospital admissions (in acute and post-acute cases) occurring each year in the Institutes of Hospitalization and Care of the Region.

The information present in the various information systems was supplemented and integrated through a deterministic record-linkage procedure, using a unique and anonymized patient code. The anonymized data from administrative databases are regularly used by the regional Health Authorities for epidemiological and administrative purposes, therefore - as required by the Italian legislation on the conduction of observational studies - it was not necessary to request either the informed consent of the patients, nor the approval of the Ethics Committee of the structures involved [11].

\section{Study population}

From the FarmED database, all subjects were identified who, in the 2010-2016 period, had received at least one prescription for one of the following drugs: dexamethasone intravitreal implant (ATC: S01BA01), intravitreal triamcinolone (ATC: S01BA05), ranibizumab (ATC: S01LA04), aflibercept (ATC: S01LA05), bevacizumab (ATC: L01XC07).

Since the prescribing indication was not available in the information system, the patients being treated for DME were identified by applying the following algorithm:

- for the users prevalent in the 2013-2015 period it was verified the presence, in the 3 years preceding the first prescription (index prescription), of at least one hospitalization with a diagnosis of DM (ICD-9-CM: 250.xx) or diabetic retinopathy (ICD9-CM: 362.x), or at least one prescription for hypoglycemic drugs (ATC: A10). Subjects who had at least one of the two conditions were defined as diabetic users of drugs for the treatment of DME; 
- among the selected diabetic users, treatment-naïve users were identified by selecting all subjects with an index prescription in the 2013-2015 period, and verifying the absence of prescription of other study drugs in the previous six months. Patients defined as "switchers" - i.e. those who, during the 12 months following the index prescription, were dispensed a drug for the treatment of DME other than that of the index prescription - were excluded from the analysis.

For the cohort of users selected by applying the described criteria, all the dispensing of the study drugs occurred in the 12 months following the index prescription were evaluated, and the number of administrations performed - and the related annual cost - were calculated, based on the regional price of the drug as indicated in the FarmED.

In addition, in order to assess the appropriateness of the treatment, the number of administrations performed in the first four months of the index prescription and the number of administrations performed during the 12 months of treatment were calculated.

The four-month window allows to evaluate the effective administration of the loading dose within a reasonable time, since the treatment with ranibizumab should be initiated with three or more consecutive monthly injections, while that with aflibercept should be started with one injection per month for three consecutive doses. The expected percentage of patients with three injections in the first four months, for both drugs, is therefore close to $100 \%$.

\section{RESULTS}

Patients in the Lazio Region, who in 2016 had received at least one prescription for the study drugs, amounted to 7,265, 43.0\% of whom received ranibizumab, 37.5\% aflibercept and the remaining 19.5\% dexamethasone intravitreal implant (i.i.). Prescriptions for intravitreal triamcinolone and bevacizumab were not identified within the information systems analyzed. As reported in Table I, the number of subjects treated has been steadily increasing from 2010 to 2016 . In 2016, around 600 subjects $-8.8 \%$ of the total - received prescriptions for two or more drugs other than those being studied: such patients, in subsequent analyses, will be referred to as "switchers".

Among total users, the mean proportion of patients with a diagnosis of diabetes confirmed by previous hospitalizations or prescriptions of hypoglycemic drugs is equal to $35.0 \%$, and in 2016 it varies between the $52.1 \%$ of subjects treated with dexamethasone i.i. and the $26.2 \%$ of aflibercept users (Table II).

The number of subjects naïve at 6 months was approximately 1,500 per year; in 2016 the percentage of naïve subjects out of the total number of users was $64.1 \%$ for dexamethasone i.i., $56.6 \%$ for ranibizumab and $49.8 \%$ for aflibercept (Table III).

\begin{tabular}{|c|c|c|c|c|c|c|c|c|}
\hline \multirow{2}{*}{ ATC } & \multirow{2}{*}{ Drug } & \multicolumn{7}{|c|}{ Patients (no.) } \\
\hline & & 2010 & 2011 & 2012 & 2013 & 2014 & 2015 & 2016 \\
\hline S01BA01 & Dexamethasone i.i. & - & 104 & 405 & 601 & 939 & 1,267 & 1.544 \\
\hline S01LA04 & Ranibizumab & 303 & 1,020 & 1,763 & 4,421 & 4,753 & 4,074 & 3.396 \\
\hline S01LA05 & Aflibercept & - & - & - & 91 & 980 & 1,946 & 2.962 \\
\hline \multicolumn{2}{|l|}{ Total } & 303 & 1,124 & 2,159 & 4,941 & 6,122 & 6,634 & 7,265 \\
\hline \multicolumn{2}{|c|}{ Switchers ( $\geq 2$ drugs) } & - & - & 9 & 172 & 550 & 653 & 637 \\
\hline
\end{tabular}

Table I. Subjects who received at least one study drug, treated for DME or other conditions (Lazio 2010-2016)

\begin{tabular}{|c|c|c|c|c|c|c|c|c|c|}
\hline \multirow{2}{*}{ ATC } & \multirow{2}{*}{ Drug } & \multicolumn{2}{|c|}{2013} & \multicolumn{2}{|c|}{2014} & \multicolumn{2}{|c|}{2015} & \multicolumn{2}{|c|}{2016} \\
\hline & & No. & $\%$ & No. & $\%$ & No. & $\%$ & No. & $\%$ \\
\hline S01BA01 & Dexamethasone i.i. & 234 & 38.9 & 406 & 43.2 & 670 & 52.9 & 805 & 52.1 \\
\hline S01LA04 & Ranibizumab & 1,641 & 37.1 & 1,782 & 37.5 & 1,488 & 36.5 & 1,175 & 34.6 \\
\hline S01LA05 & Aflibercept & 33 & 36.3 & 251 & 25.6 & 435 & 22.4 & 777 & 26.2 \\
\hline \multicolumn{2}{|l|}{ Total } & 1,812 & 36.7 & 2,218 & 36.2 & 2,304 & 34.7 & 2,450 & 33.7 \\
\hline \multicolumn{2}{|c|}{ Switchers ( $\geq 2$ drugs) } & 96 & 55.8 & 221 & 40.2 & 289 & 44.3 & 307 & 48.2 \\
\hline
\end{tabular}

Table II. Diabetic subjects who received at least one study drug. Absolute values and \% of patients with DME out of total users (Lazio 2013-2016) 


\begin{tabular}{llcc|cc|cc|cc}
\hline \multirow{2}{*}{ ATC } & \multirow{2}{*}{ Drug } & \multicolumn{2}{c|}{$\mathbf{2 0 1 3}$} & \multicolumn{2}{c|}{$\mathbf{2 0 1 4}$} & \multicolumn{2}{c|}{$\mathbf{2 0 1 5}$} & \multicolumn{2}{c}{$\mathbf{2 0 1 6}$} \\
\cline { 3 - 10 } & & No. & $\%$ & No. & $\%$ & No. & $\%$ & No. & $\%$ \\
\hline S01BA01 & Dexamethasone i.i. & 167 & 71.4 & 266 & 65.5 & 416 & 62.1 & 516 & 64.1 \\
S01LA04 & Ranibizumab & 1,402 & 85.4 & 1,152 & 64.6 & 922 & 62.0 & 665 & 56.6 \\
S01LA05 & Aflibercept & 10 & 30.3 & 103 & 41.0 & 204 & 46.9 & 387 & 49.8 \\
Switchers ( $\geq 2$ 2 drugs) & 15 & 15.6 & 11 & 5.0 & 15 & 5.2 & 21 & 6.8 \\
\hline
\end{tabular}

Table III. Diabetic subjects naive at 6 months. Absolute values and \% of total diabetic users (Lazio 2013-2016)

\begin{tabular}{|c|c|c|c|c|c|c|c|}
\hline ATC & Drug & Men (No.) & $\begin{array}{c}\text { Mean age } \\
\text { (years) }\end{array}$ & $\begin{array}{c}\text { Women } \\
\text { (No.) }\end{array}$ & $\begin{array}{c}\text { Mean age } \\
\text { (years) }\end{array}$ & Total (No.) & $\begin{array}{c}\text { Mean age } \\
\text { (years) }\end{array}$ \\
\hline S01BA01 & Dexamethasone i.i. & 317 & 67.6 & 229 & 70.1 & 546 & 68.7 \\
\hline S01LA04 & Ranibizumab & 1,483 & 69.3 & 1,205 & 72.0 & 2,688 & 70.5 \\
\hline S01LA05 & Aflibercept & 101 & 74.6 & 81 & 78.3 & 182 & 76.2 \\
\hline Total & & 1,901 & 69.3 & 1,515 & 72.1 & 3,416 & 70.5 \\
\hline
\end{tabular}

Table IV. Cohort of diabetic subjects naive at 6 months who did not switch to different drugs than the initial one. Distribution by gender and age (Lazio 2013-2015)

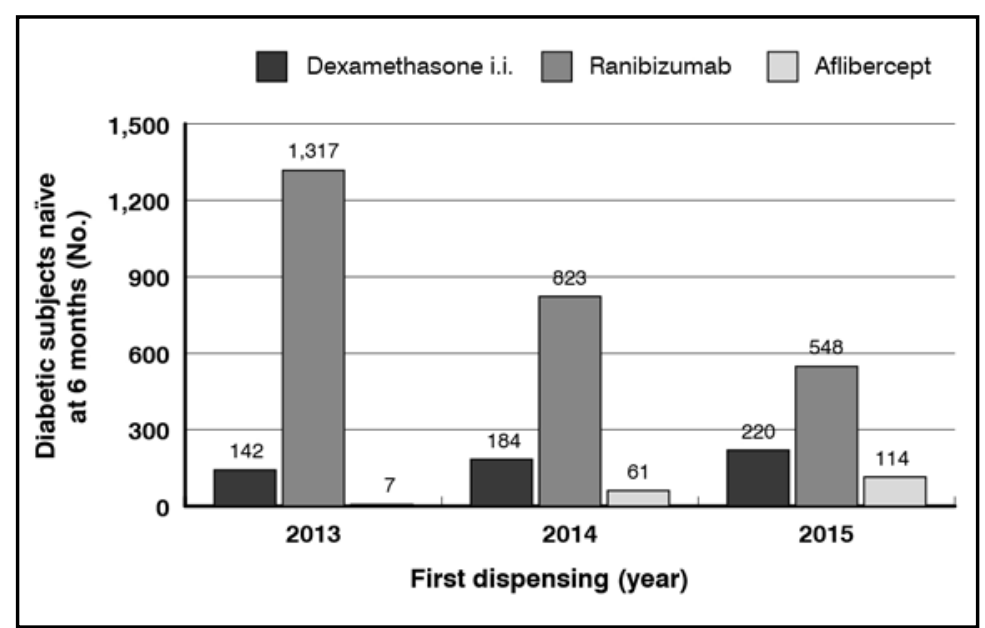

Figure 1. Cohort of diabetic subjects naive at 6 months. Distribution by drug (Lazio 2013-2015)
In order to highlight the average number of annual dispensing and the related cost, it was selected the cohort of patients naïve at 6 months, who started treatment in the 20132015 period and who did not switch to different drugs than the initial one.

In this way, 3,416 newly treated subjects were identified, of whom $78.7 \%$ started treatment with ranibizumab, $16.0 \%$ with dexamethasone i.i. and the remaining 5.3\% with aflibercept. The gender distribution of users does not vary significantly between the different drugs analyzed (about 55\% males for ranibizumab and aflibercept and $58 \%$ for dexamethasone i.i.), while the mean age is 70.5 years, varying between the 68,7 years of the subjects treated with dexamethasone

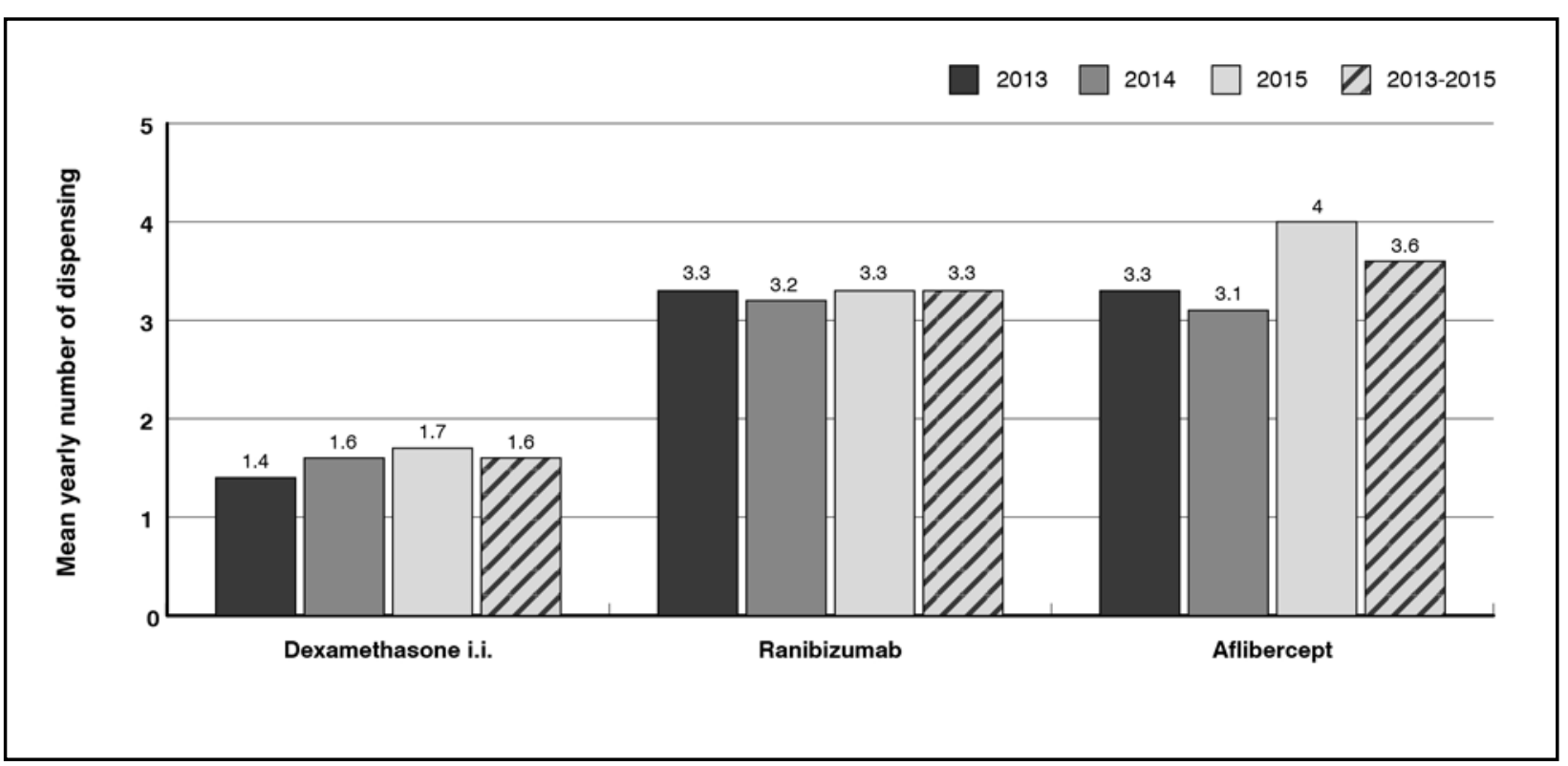

Figure 2. Cohort of diabetic subjects naive at 6 months. Mean yearly dispensing (Lazio 2013-2015) 
i.i. and the 76.2 treated of those treated with aflibercept (Table IV). The distribution by year of the subjects treated shows a reduction in the use of ranibizumab and an increase in that of dexamethasone i.i. (+54.9\%) and aflibercept (Figure 1).

The mean number of dispensing occurred within one year of the first prescription is equal to 1.6 for patients treated with dexamethasone i.i., 3.3 for ranibizumab and 3.6 for aflibercept. The starting year of treatment does not seem to affect the average number of administrations per subject; in fact, variability is minimal for dexamethasone i.i. and ranibizumab, while for aflibercept there is an increase from 3.3 to 4 yearly administrations (Figure 2).

The administrations of dexamethasone i.i. are in line with what is indicated in the prescribing information, while for ranibizumab and aflibercept - although a precise number of administrations is not specified - a potential under-use has been identified. This data is confirmed by the distribution of the subjects by number of administrations received within 4 and 12 months from the first administration. In the first 4 months, $88.5 \%$ of patients treated with dexamethasone i.i. received a dose, $10.6 \%$ received two and the remaining $0.9 \%$ received three. With regard to ranibizumab and aflibercept, on the other hand, only $36.8 \%$ and $39.0 \%$ of patients received - during the first three months - a number of prescriptions consistent with what indicated in the prescribing information, while $55 \%$ of patients received a maximum of two

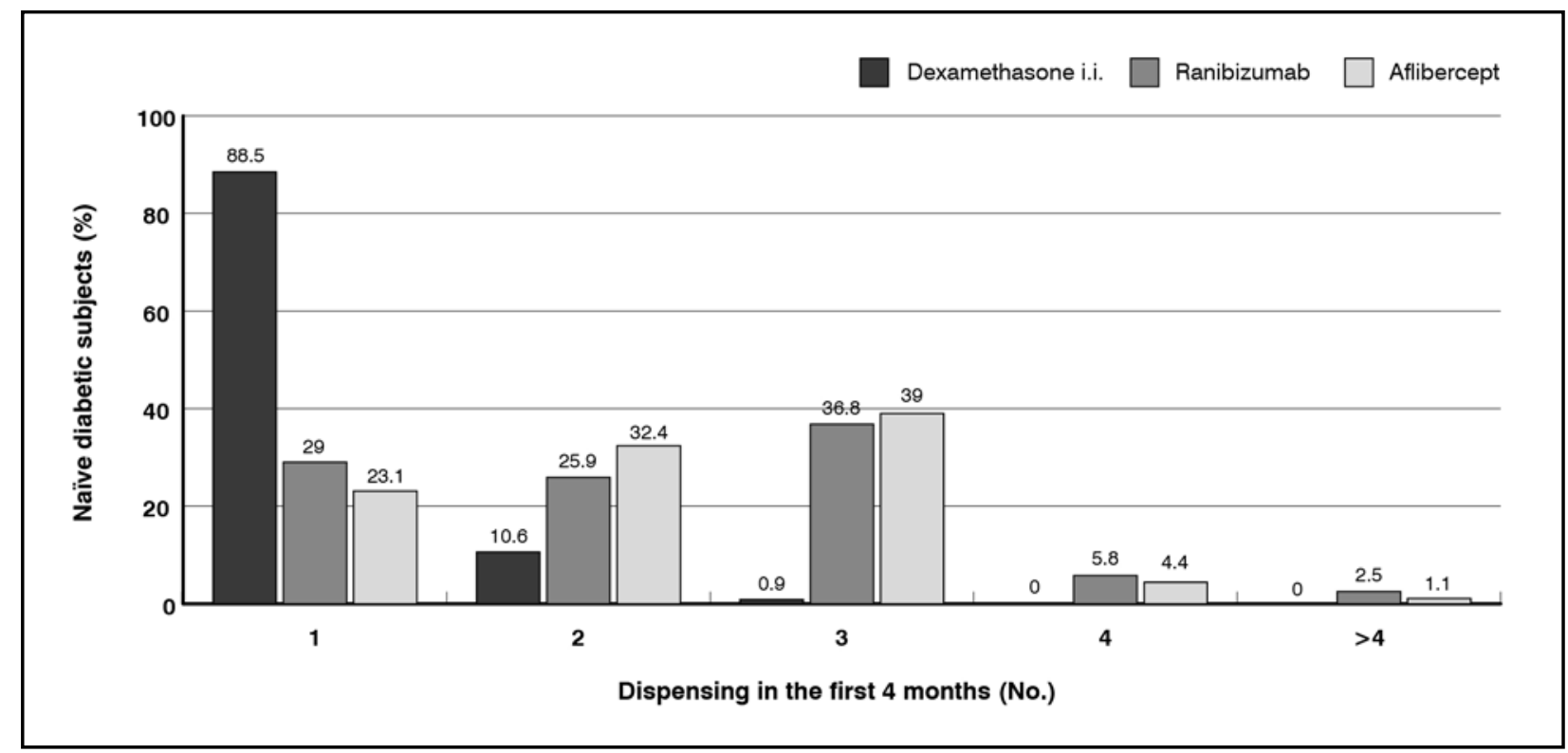

Figure 3. Distribution of naive diabetic subjects by number of dispensing in the first 4 months after the first administration (Lazio 2013-2015)

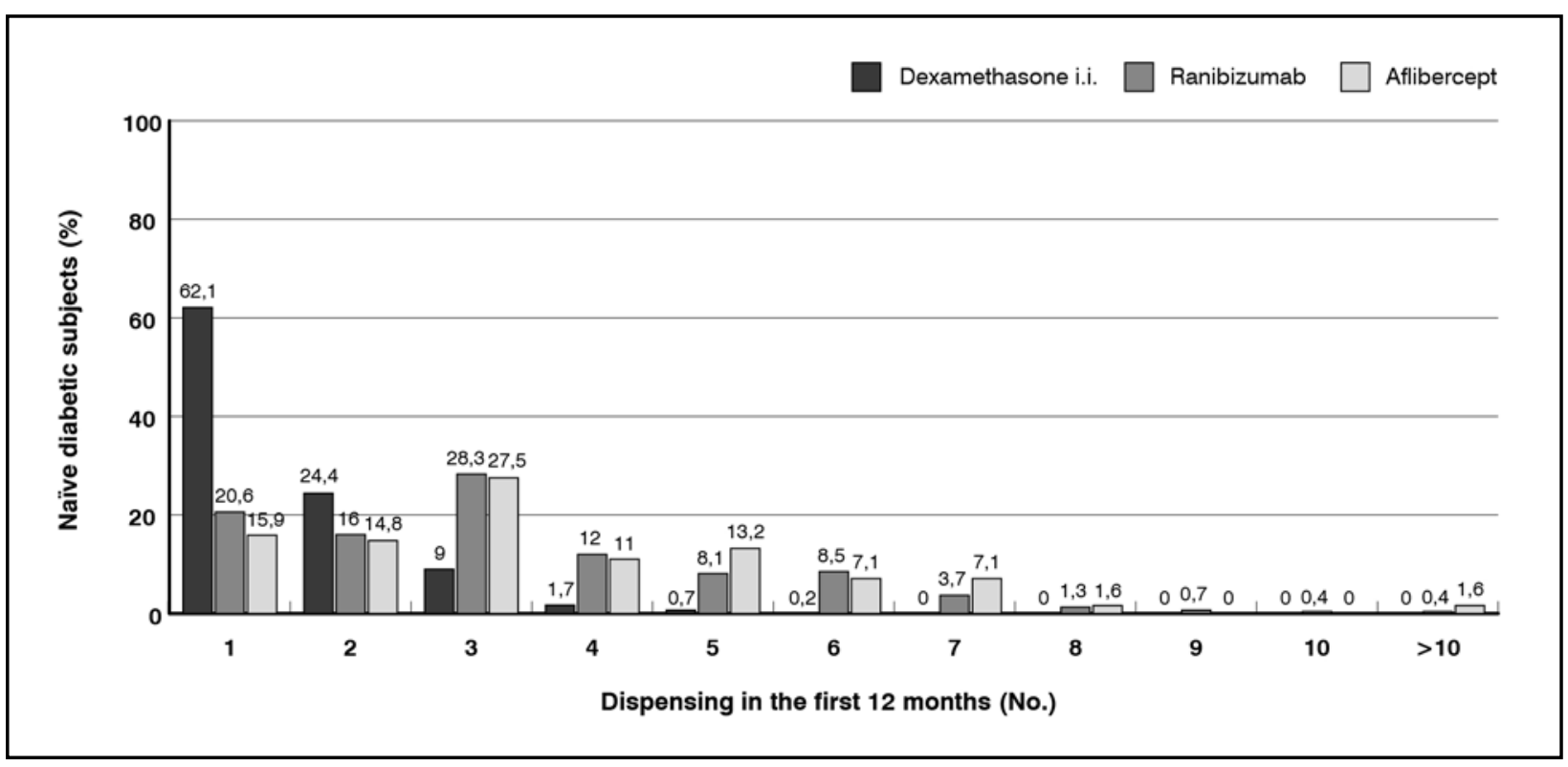

Figure 4. Distribution of naive diabetic subjects by number of dispensing in the first 12 months after the first administration (Lazio 2013-2015) 
doses, and approximately 1 in 4 patients received a single injection during the first 4 months of treatment (Figure 3). Analyzing the number of administrations in the first 10 months, it is noted that $89.9 \%$ of patients treated with dexamethasone i.i. received 2 administrations, while patients receiving at most 2 administrations of ranibizumab and aflibercept are $38.5 \%$ and $33.5 \%$, respectively, indicating a strong underuse and, consequently, a high proportion of inappropriateness (Figure 4).

The analysis repeated by stratifying by year of first treatment confirms the previous results, with a stability of the data with regard to dexamethasone i.i. and ranibizumab, while for aflibercept the proportion of undertreated patients would seem to decrease, with the proportion of subjects with at most 3 administrations in the first 10 months of treatment decreasing from $70.6 \%$ to $58.8 \%$ (Table VI).

The mean annual cost for the treatment of a patient with DME and naïve at 6 months was equal to $€ 2,388$; a total cost for only the naïve patients selected in the 2013-2015 period is therefore estimated at approximately $€ 8.2$ million. The average annual cost of dexamethasone i.i. treatment was $€ 1,497$, lower than that of ranibizumab $(€ 2,562)$ and aflibercept ( $€$ $2,485)$. No significant differences with reference to the year of start of the first treatment have been identified (Table VII).

Finally, to get an idea of the expenditure for inappropriately treated or undertreated patients, the cost of the drugs dispensed to patients receiving less than 3 administrations of ranibizumab or aflibercept in the first 10 months of treatment was considered. The total estimate was equal to $€ 1.3$ million, which probably represents, for the regional Health System, a significant cost that does not provide any benefits to patients.

\section{DISCUSSION}

Diabetic macular edema is the most serious ocular complication of DM, and one of the main causes of vision loss and blindness in industrialized Countries [12]. The progressive aging of the population - and the expected increase in the global prevalence of diabetes - will lead in the coming years to a marked increase in the ocular complication-related burden, including DME. Early diagnosis and effective treatment are essential factors in preventing visual impairment and avoiding the economic consequences and the social impact of vision loss.

\begin{tabular}{|c|c|c|c|c|c|c|c|c|c|c|c|c|c|}
\hline \multirow{2}{*}{ Drug } & \multirow{2}{*}{ Year } & \multirow{2}{*}{$\begin{array}{l}\text { Patients } \\
\text { (No.) }\end{array}$} & \multicolumn{11}{|c|}{ Dispensing (No.) } \\
\hline & & & 1 & 2 & 3 & 4 & 5 & 6 & 7 & 8 & 9 & 10 & $>10$ \\
\hline \multirow[t]{3}{*}{ Dexamethasone i.i. } & 2013 & 142 & 70.4 & 23.2 & 5.6 & - & 0.7 & - & - & - & - & - & - \\
\hline & 2014 & 184 & 64.7 & 25.0 & 9.2 & 1.1 & - & - & - & - & - & - & - \\
\hline & 2015 & 220 & 62.7 & 24.5 & 8.6 & 3.6 & 0.5 & - & - & - & - & - & - \\
\hline \multirow[t]{3}{*}{ Ranibizumab } & 2013 & 1,317 & 22.4 & 16.3 & 29.0 & 13.2 & 8.0 & 6.4 & 2.7 & 0.8 & 0.8 & 0.3 & 0.2 \\
\hline & 2014 & 823 & 20.8 & 18.1 & 31.7 & 11.9 & 8.6 & 6.2 & 1.3 & 0.9 & 0.2 & - & 0.2 \\
\hline & 2015 & 548 & 20.4 & 17.2 & 30.3 & 12.8 & 7.7 & 7.5 & 2.9 & 1.1 & 0.2 & - & - \\
\hline \multirow[t]{3}{*}{ Aflibercept } & 2013 & 7 & 28.6 & 14.3 & 28.6 & - & 28.6 & - & - & - & - & - & - \\
\hline & 2014 & 61 & 23.0 & 19.7 & 27.9 & 9.8 & 13.1 & 6.6 & - & - & - & - & - \\
\hline & 2015 & 114 & 13.2 & 14.9 & 30.7 & 13.2 & 13.2 & 8.8 & 2.6 & 0.9 & - & - & 2.6 \\
\hline
\end{tabular}

Table VI. Distribution of naive diabetic subjects by year and number of dispensing in the first 10 months after the first administration (Lazio 2013-2015)

\begin{tabular}{lllllc}
\hline \multirow{2}{*}{ ATC } & \multicolumn{1}{c}{ Drug } & \multicolumn{4}{c}{ Average cost $(\boldsymbol{E} /$ year $)$} \\
\cline { 3 - 5 } & & $\mathbf{2 0 1 3}$ & $\mathbf{2 0 1 4}$ & $\mathbf{2 0 1 5}$ & $\mathbf{2 0 1 3 - 2 0 1 5}$ \\
\hline S01BA01 & Dexamethasone i.i. & 1,326 & 1,514 & 1,593 & 1.497 \\
S01LA04 & Ranibizumab & 2,911 & 2,296 & 2,124 & 2.562 \\
S01LA05 & Aflibercept & 2,407 & 2,273 & 2,604 & 2.485 \\
Total & & $\mathbf{2 . 7 5 5}$ & $\mathbf{2 , 1 6 0}$ & $\mathbf{2 , 0 5 4}$ & $\mathbf{2 , 3 8 8}$ \\
\hline
\end{tabular}

Table VII. Cohort of diabetic subjects naive at 6 months. Average annual cost of treatment (Lazio 2013-2015) 
Our analysis, based on real-world data, allowed to estimate the number of patients in the Lazio region treated for DME in the years 2013-2016, confirming the growth trend expected on the basis of the epidemiological data. Diabetic subjects with at least one drug dispensed for the treatment of DME have in fact increased from about 1,800 in 2013 to 2,450 in 2016.

Based on literature data - which in 2015 estimated the diabetic population of Lazio at $6.6 \%$ of residents [13] and an incidence of DME with visual impairment among diabetics of $2.0 \%$ [14] - the population of DME patients in 2015 was approximately 7,800. In our analysis, DME patients who received at least one treatment in 2015 were 2,300, which means that health information systems have identified about $29.7 \%$ of total patients. Even considering the recording and tracking errors typical of the information systems, the remaining portion could be made up of subjects who do not receive any drug therapy.

Currently, the drug therapy for the treatment of DME includes the use of corticosteroids or anti-VEGFs (vascular endothelial growth factor receptor antagonists) [15]. Corticosteroids can be administered locally (intravitreal injections) or by controlled-release intravitreal implants, which have a therapeutic effectiveness sustained over time and a frequency of 2-3 administrations per year, while anti-VEGFs are administered by intravitreal injection approximately every 4-6 weeks [15].

The results of our analysis allowed to estimate the average number of annual administrations in the cohort of patients/users in the 2013-2015 period, highlighting - among the subjects treated with dexamethasone i.i. - a substantial adherence to the prescribing indication, and at the same time a substantial proportion of patients treated with ranibizumab and aflibercept in a potentially inappropriate way (lower number of administrations than in common clinical practice).

The issue of adherence to treatment in DME was addressed in a position paper of the Italian Pharmacology Society (SIF, Società Italiana di Farmacologia) [16], which highlights how in real-life observational studies the number of anti-VEGF administrations is always lower than the expected administration schedule while, in the case of corticosteroid intravitreal implant, a number of administrations variable from 1 to 3 was found, in line with what specified in the prescribing information.

As reported in the literature [17-21], in the treatment of DME the lack of adherence to the recommended therapeutic regimen results in a missed or reduced improvement in visual acuity. In addition, it represents one of the main problems of the National Health Service, since it causes the use of resources without a corresponding clinical benefit. The delay or lack of treatment can in fact lead to the loss of vision, with subsequent implications for the patient such as a reduced quality of life and autonomy, social isolation and reduction of job opportunities. All this, in the long term, translates into an increase in the costs borne by the Health Service and society [22].

In our analysis, the potential inappropriateness identified in the treatment with ranibizum$\mathrm{ab}$ and aflibercept leads to an expense, in relation to patients treated with less than 3 yearly administrations (instead of the expected 6-7), of $€ 1.3$ million, which is likely unaccompanied by any clinical benefit. In a period of reduction of the available resources - and therefore of spending review - it is necessary to evaluate the allocation of resources and the adherence of patients to the prescribed treatments, in order to ensure the access to treatment to the greatest possible number of patients.

\section{CONCLUSIONS}

Designing a care pathway that tends to guarantee a greater appropriateness of the drugs prescribed, accompanied by an optimal adherence to therapy, would strongly reduce, in the specific case of the treatment of DME, the current waste of resources (in fact, if the interventions are inappropriate and characterized by poor adherence, they represent a waste), with a consequent increase in the effectiveness of interventions and a correct use of resources.

\section{Funding}

The publication fee was sponsored with unconditional support by Allergan Spa.

\section{Conflicts of interest}

The authors declare that they have no conflicts of interest in this research. 


\section{REFERENCES}

1. Osservatorio ARNO Diabete - Il profilo assistenziale della popolazione con diabete Rapporto 2015 - Volume XXIII Collana “Rapporti ARNO”. Cineca, SID

2. ISTAT - Il Diabete in Italia - Anni 2000-2016. Luglio 2017

3. ALTIS. White Paper-Retinopatia diabetica: una lotta possibile. I quaderni di IHPB - Italian Health Policy Brief. 2016

4. Marcellusi A, Viti R, Mecozzi A, et al. The direct and indirect cost of diabetes in Italy: a prevalence probabilistic approach. Eur J Health Econ 2016; 17: 139-47; https://doi. org/10.1007/s10198-014-0660-y

5. Marcellusi A, Viti R, Sciattella P, et al. Economic aspects in the management of diabetes in Italy. BMJ Open Diabetes Res Care. 2016; 4: e000197; https://doi.org/10.1136/ bmjdrc-2016-000197

6. Brambati M, Cicinelli MV, Lattanzio R, et al. Nosography, screening, and diagnosis of diabetic retinopathy. Giornale Italiano di Diabetologia e Metabolismo 2018; 38: 76-82

7. Zheng Y, He M, Congdon N. The worldwide epidemic of diabetic retinopathy. Indian J Ophthalmol 2012; 60: 428-31; https://doi.org/10.4103/0301-4738.100542

8. Zhang X, Saaddine JB, Chou CF, et al. Prevalence of diabetic retinopathy in the United States, 2005-2008. JAMA 2010; 304: 649-56; https://doi.org/10.1001/jama.2010.1111

9. Bourne RR, Stevens GA, White RA, et al. Causes of vision loss worldwide, 1990-2010: a systematic analysis. Lancet Glob Health 2013; 1: e339-49; https://doi.org/10.1016/S2214109X(13)70113-X

10. Heng LZ, Comyn O, Peto T, et al. Diabetic retinopathy: pathogenesis, clinical grading, management and future developments. Diabet Med 2013; 30: 640-50; https://doi.org/10.1111/ dme. 12089

11. Agenzia Italiana del Farmaco. Determinazione 20 marzo 2008. Gazzetta Ufficiale della Repubblica Italiana - Serie Generale n. 76, 31-3-2008

12. Zhang X, Saaddine JB, Chou CF, et al. Prevalence of diabetic retinopathy in the United States, 2005-2008. JAMA 2010; 304: 649-56; https://doi.org/10.1001/jama.2010.1111

13. Epicentro. Diabete: dati di prevalenza a livello nazionale. Available at http://www.epicentro. iss.it/igea/diabete/prevalenza.asp\#istat (last accessed June 2019)

14. Marino M, Avolio M, Poscia A, et al. Edema Maculare Diabetico e introduzione dell'impianto a lungo rilascio di desametasone. QIJPH 2015; 4, 1-12

15. Informatore Farmaceutico on-line. Available at: http://www.codifa.it/ (last accessed June 2018)

16. Caputi AP, Rossi F. Farmaci intravitreali nelle malattie retiniche: proprietà farmacologiche e aderenza alla terapia. SIF, 2015. Available at https://www.sifweb.org/documenti/guideline_2015-01-01 (last accessed June 2019)

17. Holz FG, Tadayoni R, Beatty S, et al. Multi-country real-life experience of anti-vascular endothelial growth factor therapy for wet age-related macular degeneration. Br JOphthalmol 2015; 99: 220-6; https://doi.org/10.1136/bjophthalmol-2014-305327

18. Holz FG, et al. Safety of ranibizumab in routine clinical practice: 1-year retrospective pooled analysis of four European neovascular AMD registries within the LUMINOUS programme. Br J Ophthalmol 2013; 97: 1161-7; https://doi.org/10.1136/bjophthalmol-2013-303232

19. Cohen SY, Mimoun G, Oubraham H, et al. Changes in visual acuity in patients with wet age-related macular degeneration treated with intravitreal ranibizumab in daily clinical practice: the LUMIERE study. Retina 2013; 33: 474-81; https://doi.org/10.1097/ IAE.0b013e31827b6324

20. Pagliarini S, Beatty S, Lipkova B, et al. A 2-Year, Phase IV, Multicentre, Observational Study of Ranibizumab $0.5 \mathrm{mg}$ in Patients with Neovascular Age-Related Macular Degeneration in Routine Clinical Practice: The EPICOHORT Study. J Ophthalmol 2014; 2014: 857148; https://doi.org/10.1155/2014/857148

21. Hariprasad SM, Morse LS, Shapiro H, et al. Fixed monthly versus less frequent ranibizumab dosing and predictors of visual response in exudative age-related macular degeneration. J Ophthalmol 2012; 2012: 690641; https://doi.org/10.1155/2012/690641

22. Yuzawa M, Fujita K, Tanaka E, et al. Assessing quality of life in the treatment of patients with age-related macular degeneration: clinical research findings and recommendations for clinical practice. Clin Ophthalmol 2013; 7: 1325e32; https://doi.org/10.2147/OPTH.S45248 